\title{
Persoonlijke blik op verleden en toekomst*
}

\author{
J.H.G.C. Elzinga**
}

Het verzoek om voor het Lutje PJG een terugblik te geven vanuit persoonlijke (werk-)ervaringen bij de Rijkspolitie, alsmede een blik in de toekomst, gaf aanleiding tot een zoektocht; een poging om het verleden te reconstrueren en eventueel lijnen naar de toekomst door te trekken. In de lezing voor het Lutje PJG heb ik verteld over een door mij in het begin van de jaren zeventig geschreven beleidsplan. De centrale vraag daarin was: 'Hoe ga je om met overtredingen?' In die tijd was ik vrijwel de enige die daar in geïnteresseerd was en daar onderzoek naar deed. De rode draad in mijn verhaal wordt gevormd door hetgeen geschiedde op het vlak van de overtredingen en alles wat daarmee samenhangt, omdat ik dacht en denk dat het ook belangrijk is aandacht te schenken aan het kleine. Natuurlijk hadden we bij de Rijkspolitie ook oog voor de bestrijding van criminaliteit, maar dat liep nog best redelijk en het opsporingspercentage was zelfs relatief goed. Gedurende mijn zoektocht kwam langzamerhand een aantal vragen naar voren:

- $\quad$ was er - nu al weer enige tijd geleden - sprake van een 'redelijke beheersing' van dat deel van de politietaak waar ik mede verantwoordelijk voor was?

- is er een verklaring voor het afbrokkelende gezag van de politie en voor de toename in geweld? en

- hoe zal het in de toekomst gaan?

Bij de totstandkoming van het nu volgende verhaal hebben deze vragen geleid tot de formulering van vier thema's die hieronder worden besproken.

Eerst wordt een beschrijving gegeven van ontwikkelingen in de uitoefening van de politietaak. Vervolgens wordt ingegaan op ontwikkelingen die zich in de politieorganisatie hebben voltrokken. Daarna komen enkele maatschappelijke ontwikkelingen aan de orde en tenslotte wordt een korte blik in de toekomst geworpen. Mijn ervaring bij de politie is voornamelijk gebaseerd op het werken in een

* Dit verslag van de lezing voor het Lutje PJG is mede tot stand gekomen door een vraaggesprek dat Jan Nijboer, criminoloog aan de RUG, met de heer Elzinga heeft gevoerd. Het heeft daardoor enigszins het karakter van een verhaal in spreektaal gekregen.

** Oud-districtscommandant van de Rijkspolitie te Groningen. 
district, dat wil zeggen in de kleinere gemeenten. Daarop is mijn verhaal dan ook goeddeels gebaseerd.

\section{Ontwikkelingen in de uitoefening van de politietaak}

Ik ben opgegroeid met politieambtenaren op het platteland, die gevoel hadden voor hun baan. Het waardevolle was dat zij er ook woonden, hoewel dat tegelijkertijd een zware belasting was. Als er iemand in hun vrije tijd bij de achterdeur kwam, stuurden ze die niet weg. Zij kenden de bevolking. Groepscommandanten of postcommandanten hadden vroeger contact met scholen. Ze gingen in burger naar een school om te praten. Het was een kleine gemeenschap, met een geïnteresseerde burgemeester. De politie moest ook een soort EHBO-functie vervullen. Onze filosofie was om te helpen waar je kunt, maar zo kort mogelijk en het dan weer over te geven aan anderen. Toen ik bij de Rijkspolitie begon, moest een politieambtenaar na vier jaar verhuizen, anders werd hij te eigen. Maar dat werkte niet. Net als mensen ingevoerd waren, moesten ze weer verder. In het begin mocht je ook nog geen lid zijn van een vereniging. Daar is eveneens een eind aan gemaakt. Je moet juist wel deelnemen aan het maatschappelijk leven. Het is belangrijk dat een politieman functioneert, werkt en woont in de eigen woonplaats. Als hij goed is, kan hij daardoor vertrouwen en respect opbouwen. Dat was zo in de jaren zestig. Die politieman was daardoor ook een goede informatiebron en dat leidde tot een hoog opsporingspercentage. We konden al die bronnen gebruiken en als je die weghaalt, dan haal je in één klap heel veel informatiemateriaal weg. Dat is begonnen ten gevolge van een langdurig tekort bij het Korps Rijkspolitie en het is nog versterkt voortgezet toen de politie gereorganiseerd werd, waarbij dat Korps werd opgeheven.

In die beginjaren konden we de zaak nog redelijk handhaven. De jaren zestig vormden echter het begin van grote veranderingen. Langzaam maar zeker ontdekte ik zelf ook allerlei dingen. In 1964 ben ik districtscommandant geworden. Ik was jong en ik wou heel veel. Ik had bepaalde opvattingen over democratisering, maar na een aantal jaren kwam ik er achter dat ik in een veel te hoog tempo plannen had gemaakt en dat ik ze niet goed had doorgesproken. De politiemensen wilden wel veranderen van beleid, maar ze wilden het ook graag begrijpen. Dat is een geweldige ommezwaai geworden. Ik moest er veel meer tijd in stoppen. Ik ging naar de basis om het uit te leggen, als het moest tien keer, in de hoop dat het overkwam. Als je een grote ombuiging wilt maken, dan moet je er zelf ook erg veel energie insteken. 
Tot aan de jaren zeventig - de periode van de democratisering had zich inmiddels al ruimschoots ingezet - had de politie nog gezag. Daarna brokkelde dat af en werd het moeilijker het gezag te handhaven. Ondanks onze eigen tekorten werden onze politiemensen onder andere naar Amsterdam gestuurd voor assistentie. Intussen heb ik begrepen dat de Amsterdamse dienders dan wel met vakantie gingen. We waren in het dorp gewend om een beetje de orde te handhaven. Op het trottoir fietsen hoorde niet, bij de bocht moest je een hand uitsteken en je achterlicht moest het ook doen. Onze mensen kwamen dan terug uit Amsterdam waar auto's driedubbel geparkeerd stonden en waar ze werden ontvangen met de kreet: 'De norm hier is per maand twee verbalen, niet meer'. Er kwam een aantal mensen gedeukt terug. Die zeiden: 'Moet ik nou hier achterlichtjes gaan bekeuren?'. Dat was een vroeg begin van een zekere vorm van normvervaging. Later begonnen burgers - met verwijzing naar Amsterdam - ook te zeggen dat niet op alle slakken zout moest worden gelegd. Wij waren als politieorganisatie niet voorbereid op die verandering, op een tolerantere maatschappij. De Amsterdamse politie raakte in de war toen Koosje Koster krenten ging uitdelen. Daar zou je nu om lachen. Maar de Amsterdamse politie moest wél de kastanjes uit het vuur halen toen de maatschappelijke tolerantie groter werd.

Wat ik politici kwalijk neem, is dat ze daar bij tijd en wijle in voorop liepen. Het was de tijd dat wetenschappers begonnen te vertellen dat de schuld niet bij de dader lag, maar bij de ouders, de maatschappij of de school. Dat is een langzaam verlopend proces geweest, waarbij de politie op een gegeven moment ook dacht dat kleine overtredingen misschien niet meer zo belangrijk waren. Daar kwam bij dat we een groot tekort hadden en dan is het excuus al gauw gevonden. Een aantal dingen werden niet meer gedaan. Je had in die tijd ook nog geen overzicht. Er werden allerlei incidentele beslissingen genomen, waarvan pas later bleek dat ze op langere termijn allerlei gevolgen hadden. Overtredingen werden bijvoorbeeld zo massaal dat we er niets meer aan konden doen. Dat vonden we toen wel erg, maar goed, dat was zo.

Het was echter wel een kwestie van verzwakking. Het OM stelde op een gegeven moment - vrij recent overigens - dat men zich ging richten op het uitgaansgeweld en daarom zouden kleinere misdrijven niet meer worden vervolgd. Dat was dus exact hetzelfde wat we eerder met de overtredingen hebben beleefd, maar nu nog een graadje erger. Langzamerhand glijd je dan af. Ik heb geprobeerd een verklaring te vinden waarom het gezag van de politie afbrokkelde, minder werd. Vroeger was het zo dat als één diender zei: 'Het moet afgelopen zijn', dan was het zo. Die tijd is voorbij. 


\section{Ontwikkelingen in de politieorganisatie}

Er heeft zich de afgelopen 25 jaren een centralisatie voltrokken die een aantal negatieve effecten met zich mee bracht. Ik heb het voor mijn ogen zien gebeuren, ook toen ik nog bij de Rijkspolitie was. Op het platteland zaten we al onder druk vanwege de personele en financiële tekorten. Daarnaast werden we vaak zwaar belast. De rijksgebouwendienst, die altijd het onderhoud deed, gaf die taak door aan Justitie. Justitie zat in de problemen, had te weinig geld voor onderhoud. Het gevolg was dat twee, drie jaar na mijn vertrek, een groot aantal politiebureau's moest worden verkocht, omdat er geen geld was. Dat was weer een stap achteruit. Het vaste punt in het dorp dat mensen kenden, het bureau, ging weg en dat proces is in feite voortgezet na de reorganisatie. Want toen zijn bijna alle kleine bureau's verkocht en zijn heel veel politiemensen van het platteland weggetrokken.

Naar aanleiding van Oosterparkrellen (30 december 1997) kwam weer naar voren dat er een groot aantal buurtagenten bij moesten komen. Brand (hoofdcommissaris a.i.) heeft dat sterk bepleit, maar twee jaar daarvoor was ook al door de toenmalige regiochef in Drenthe bij zijn afscheid gezegd dat we weer terug moesten naar de dorpen. Ik ben begonnen bij de gemeentepolitie in Groningen. Toen hadden we nog wijkbureau's, maar opeens moest alles gecentraliseerd worden. Die wijkbureau's zijn indertijd verdwenen, maar later, in de tijd van Nordholt, is er weer een systeem ingevoerd van wijkgebonden werken. Hoe het nu verder moet, weet ik niet. Toch is het wel verstandig om per kleiner gebied één of twee vaste politieambtenaren te hebben, die de bevolking leren kennen en die omgekeerd vertrouwen genieten en een signaalfunctie hebben. De ervaren mensen zagen dat al veel eerder. Gebiedsgebonden zorg is overigens geen uitvinding van de Rijkspolitie geweest. Het was gewoon een uitvloeisel van de gemeentestructuur. Elke gemeente moest wettelijk een post- of rayoncommandant hebben. Gebiedsgebonden zorg was niet onze verdienste, hooguit dat we het tot het bittere einde hebben volgehouden.

Mijn standpunt is dat je niet meer moet centraliseren dan strikt nodig is. Dat wil zeggen, decentraal tenzij. In feite gaat het natuurlijk om een mengvorm. Als je kleinere eenheden hebt, dan geef je die een aantal randvoorwaarden. Binnen die randvoorwaarden zijn ze vrij. Je moet bijvoorbeeld het hele etmaal bestrijken, je moet met twee of drie groepen samen dag en nacht bedekken. Daarnaast heb je een systeem voor het maken van dienstroosters, jaarplanningen, een systeem van actiepunten. Binnen dat kader kan de groep eigen voorstellen doen. Het beleid geeft in hoofdlijnen aan hoe het moet, maar de tactiek en de uitvoering moet je zo laag mogelijk houden. Dat is ons allemaal goed bevallen en dat gold ook voor het $\mathrm{OM}$ en het bestuur. Ik ben daarbij nadrukkelijk geen voorstander van een 
zelfstandige politie. Het OM en het bestuur moesten de hoofdlijnen van het beleid aangeven, de politie het afgeleide beleid, de tactiek en de uitvoering.

Het idee dat je de openbare orde van situatie tot situatie moet bekijken, heb ik opgedaan op een studieconferentie. Het gaat om het plaatselijk niveau van rust. Wat je bijvoorbeeld in Uithuizen, met een gezagsgetrouwe bevolking, kunt toestaan, kan niet in Oude Pekela, waar men veel anarchistischer is. Er is ook een verschil tussen incidentele en structurele problemen. Als er bijvoorbeeld in Middelstum tijdens de Oudejaarsnacht gedonder was met het doorsnijden van brandslangen, dan was dat een incident en dan kon je de gummiknuppel gebruiken. De volgende dag werden er excuses aangeboden. Er was teveel gedronken, en of er alsjeblieft geen verbalen kwamen. In zo'n incidentele situatie kun je best geweld gebruiken.

Met de staking in de strokartonfabrieken in de Pekela's in de jaren zeventig was het een heel ander geval. Ik werd gebeld door twee burgemeesters. De één wilde erop af, de ander niet. En de werkgever zei: 'Poort vrijmaken'. Maar ik had het verhaal gehoord van Pekela. Van de uitbuiting en de ellende. Dat was niet zomaar een staking, maar er ging een geschiedenis van honderd jaar ellende aan vooraf. Slaan, duwen en trekken helpt dan niet. Dan zou ik mijn personeel daarna weg kunnen halen, want die zijn daar dan uitgepoept. Dat is dus het verschil tussen incidenteel en structureel. Zonder de achtergrond goed te kennen, kun je niet reageren. Dan moet je voorzichtiger zijn. De werkgevers waren daar helemaal niet blij mee.

De burgemeesters waren toen geen beheerder, wel bevoegd gezag, maar ik had uiteraard namens de Minister van Justitie - het beheer. Binnen de 'driehoek' speelde ook de officier van justitie zijn rol. En de Commissaris der Koningin hield ons in evenwicht. Die zei overigens ook: 'Je mag fouten maken, maar nooit de fout dat je mij niet informeert'. De burgemeesters wisten dat. Als toen het beheer bij de burgemeesters had gelegen, dan waren er zo'n twintig burgemeesters gaan praten over het probleem van Pekela. Je kunt het de burgemeesters niet kwalijk nemen dat ze voor hun eigen belangen opkomen. Maar het is een weeffout om één burgemeester als korpsbeheerder min of meer de baas te maken over de andere burgemeesters uit de regio. Het werkt niet, ze vergaderen zich blind om het eens te worden. Het is fout geweest om het beheer in handen te leggen van de burgemeesters die tegelijkertijd gezagsdragers zijn, handhavers van de openbare orde, en zo. En die bovendien allemaal tegengestelde belangen hebben, iedereen kijkt naar zijn eigen gemeente.

De reorganisatie heeft een eindeloos overlegcircuit gebracht. Dat moest wel, maar het heeft meegebracht dat er teveel mensen naar centrale punten werden getrokken. Er kwam een te sterk top-down beleid, waarin de basis niet meer aan 
bod kwam. Zodra de basis het gevoel krijgt niet meer te kunnen volgen waar de top mee bezig is, groeit er iets scheef. Je moet op een lager niveau bekijken wat je mensen kunt bieden aan ruimte om zelf in te vullen. Dat werkt ook psychologisch, want mensen willen niet teveel op de vingers gekeken worden.

Er komt ook nog bij dat de problemen in de grote steden zo hard spelen voor de korpsbeheerder, dat het nog maar de vraag is of hij/zij aandacht heeft voor de problemen in de regio. Het gaat niet meer aan om de problemen van het platteland te bagatelliseren. Toch gebeurt dat ook binnen de politie.

Het project kwantificering politie is al gestart voor de reorganisatie. Het was de bedoeling dat er meer mensen naar de grote steden zouden gaan, maar de eerste uitkomst was net andersom. Dat kon natuurlijk niet en toen is de norm aangepast, onder andere op het punt van aanrijtijden en preventietaken. Bij de huidige discussies over de politietaak spelen de aanrijtijden nogal eens een belangrijke rol. Zo zelfs, dat politieambtenaren die gaan manipuleren. De norm voor de aanrijtijd is bijvoorbeeld 15 minuten. De politieambtenaar is onderweg, maar haalt het niet in die tijd. Hij zegt dan na 15 minuten tegen de meldkamer dat de plaats van het misdrijf is bereikt en rijdt nog enige minuten door. Dan lijkt iedereen tevreden en is het doel weer bereikt. De feitelijke oorzaak - een tekort aan mankracht - wordt daarbij onder het kleed geveegd. Als je je verder teveel richt op 'meten is weten', dan is het risico dat je mensen weghaalt bij preventieve taken, om ze maar zoveel mogelijk te laten scoren.

Tussen de veranderingen van de jaren zestig en de reorganisatie bij de politie zit eigenlijk nog een andere fase. Dat is voor de Rijkspolitie een heel belangrijke fase geweest, namelijk die van de deconcentratie in het midden van de jaren tachtig. De politiek vond ineens dat het grootste deel van de bevoegdheden van het centrale punt, dat is de inspectie, naar de districten moest. Daar is toen een projectgroep voor aangesteld, waar ik lid van ben geweest. Dat zijn ontzettend boeiende jaren geweest. We kregen eindelijk veel meer bevoegdheden. Executief hadden we die al, maar nu ook op het gebied van beheer, zowel financieel als personeel. We konden meer, we stonden dichter bij de basis. Je hoefde niet iedere keer 'nee te verkopen'. Dat werd afgerond met een heel goed inspectiesysteem en dat heeft twee jaar gewerkt. Dat hield in dat ze bij je kwamen, alles onderzochten, je sterke en zwakke punten. En daarvan werd dan gezegd: 'Als je hulp wilt hebben, zullen we je helpen, zeg maar wat je wilt'. Ik ben eind 1987 vertrokken bij de Rijkspolitie. Toen was de deconcentratie al een tijdje rond. Twee jaar later werd de Rijkspolitie opgeheven en toen was het werk voor een goed deel voor niets geweest.

We hebben nu regionale politie. Maar een deel van de tweede kamer was heel wat anders van plan. Het zou politie moeten worden die georganiseerd was op 
basis van de Wet Gemeenschappelijke Regeling. Enkele kamerleden waren daar sterk voor en zij duwden wat zij konden teneinde te bereiken dat de regio's gelijk zouden worden aan die van deze Wet. Gelukkig is die ramp afgewenteld omdat Hirsch Ballin dat niet wilde. De reorganisatie zelf was beheersmatig rampzalig. Het was onverstandig, maar het was natuurlijk ook raar dat er twee soorten poli-tie naast elkaar bestonden. Als Rijkspolitie en gemeentepolitie kwam je elkaar regelmatig tegen. Bij de gemeentepolitie was de burgemeester beheerder en bij de Rijkspolitie formeel de Minister van Justitie. Een vreemde situatie met overeenkomstige gevolgen.

In het begin van de jaren zeventig heb ik in het Tijdschrift voor de Politie een pleidooi gehouden voor provinciale politie. Wel heb ik gezegd dat de grote steden, Amsterdam, Rotterdam en Den Haag, daar buiten moesten vallen. Dat moesten zelfstandige korpsen blijven. Daarmee heb ik me de woede van de secretaris-generaal op de hals gehaald. Het werd gezien als verraad aan het korps. Bovendien vroeg ik - vanwege de tekorten - waarom er geen politiedienstplicht kon worden ingevoerd. Toen werd ik helemaal afgemaakt. Dat was belachelijk. Maar het idee van een provinciale politie had ik niet zelf bedacht. Daar is voor de tweede wereldoorlog al eens in een wetenschappelijk tijdschrift over geschreven. Vele jaren later, kwam er tot mijn grote vreugde opeens een kamervoorstel voor provinciale politie. Toxopeus heeft nog een studie laten doen naar de uitvoerbaarheid en dat leverde een positief resultaat op. De VNG was echter mordicus tegen en ook de burgemeesters/kamerleden, want die zijn altijd van mening geweest dat zij de baas moesten zijn over de politie. Daardoor is het wetsvoorstel teruggetrokken.

Als er nu provinciale politie was gekomen, dan had je een beheerder gekregen die een werkrelatie met de burgemeester heeft, die evenwicht kan brengen en die knopen kan doorhakken, die verstandige beslissingen kan nemen als de burgemeesters het niet eens kunnen worden. Dan kunnen die zich bezighouden met hun feitelijke verantwoordelijkheid, de openbare orde. De CdK zou beheerder moeten worden, zoals in het teruggetrokken wetsvoorstel stond. Ik heb het voordeel gehad te mogen werken met commissarissen met evenwicht en met gezag. Als de CdK beheerder was geworden, dan hadden de provinciale staten ook een rol kunnen spelen. Het huidige regiocollege heeft geen democratische inbreng, is geen verantwoording schuldig. Maar als bij provinciale politie, de provinciale staten het niet eens zouden zijn met de korpsbeheerder of met de korpschef, dan zouden ze de begroting kunnen afstemmen. Ik vind dat de politie democratisch moet zijn ingebed. De Rijkspolitie was dat op het oog ook wel, maar in feite was de afstand tussen de tweede kamer en de districten te groot. Door dat te vinden nam ik eigenlijk afstand van het korps en daarom was men toendertijd ook zo boos op mij. Er komt nu misschien op termijn een sterk gedecentraliseerde nati- 
onale politie. Dan heb je het model van de Rijkspolitie min of meer terug. Maar maken ze dan ook de CdK beheerder? Ik vrees van niet.

\section{Maatschappelijke ontwikkelingen}

De omgang met jongeren is veel moeilijker geworden. Veel drinken gebeurde vroeger ook wel. Veel politiemensen moesten zich vroeger bij wijze van spreken invechten door als het een keer fout ging een café leeg te halen. Het verschijnsel is niet helemaal nieuw, maar het is wel veel massaler geworden. Vroeger had op het platteland ook niet zoveel problemen met drugs. Er waren incidenteel wel vernielingen, maar niet zo veel als nu. Jongelui hebben veel meer geld. Het opvoeden van kinderen is blijkbaar ook veel moeilijker geworden. Maar het is niet helemaal nieuw. Toen in Amsterdam de provo's begonnen, was er een historicus die een parallel trok met rellen in het vroegere Padua. Alleen waren daar toen nog geen bromfietsen, om eens wat te noemen. De politie moet ook in historische zin begeleid worden. Door mensen die parallellen kunnen trekken, die aan kunnen geven wat de oorzaken van ordeproblemen zijn.

De cafésluiting hadden we bijvoorbeeld aardig in de hand. Maar dat moest geliberaliseerd worden. Dat vond het VNG en dat vonden sommige burgemeesters. $\mathrm{Nu}$ is de hele nacht vrijgegeven en het is uit de hand gelopen. Houseparties vind ik iets verschrikkelijks. Als het uit de hand is gelopen, probeer het dan maar eens terug te krijgen, dat kan nooit meer op een normale manier.

In de jaren zeventig kregen we opeens bericht dat als een politieman een klap met de gummistok gaf, dat gerapporteerd moest worden. Dat rapport moest in zevenvoud opgemaakt worden. Die rapporten kwamen dus niet. De enige angst was dat de PG in Leeuwarden er iets over zou lezen. Ik denk dat het geen tien jaar meer duurt en dan heeft de politie weer meer bevoegdheden. Het is altijd een golfbeweging, dat kan haast niet uitblijven.

De rellen rond het kampioensfeest van Feyenoord in Rotterdam hebben een maatschappelijke achtergrond. Men heeft vaak een gsm'etje, er wordt teveel gedronken. Er is meer welvaart en de maatschappij is toleranter geworden. Dat was vroeger niet zo, maar ga dat nu maar eens terughalen. Probeer maar eens een houseparty te verbieden. Misschien kun je mensen op jonge leeftijd nog redden. Je moet mensen wel individueel benaderen. Het is vandaag wel moeilijker geworden dan in mijn tijd. De overheid denkt dat ze er met een koopje af kan komen. Maar dat is niet zo. Ze geeft kapitalen uit aan de organisatie van een evenement, maar dan zal er toch voldoende geld moeten zijn voor begeleidende maatregelen. 


\section{Een blik in de toekomst}

Er komt een grote uittocht van politieambtenaren aan. Tegen 2012 is éénderde van de nu in functie zijnde politieambtenaren weg. En dat is al heel lang bekend. De werving loopt tot nu toe slecht. Ik weet dat ze nu al mensen met minder opleiding inzetten. Men zint op maatregelen - er is een centraal telefoonnummer ingesteld waar geïnteresseerden zich kunnen melden. En dat lukt ook ten dele, maar het aantal afvallers daarna is groot. Het imago van de politie is voorts niet zo goed, volgens een onderzoek zelfs slechter dan dat van het leger. Maar er is nog geen geld gekomen om dat te verbeteren. Voor zover ik weet, is de motivatie aan de basis nog wel goed. Maar er is wel een vacuüm ontstaan. De top is het contact met de basis ten dele kwijtgeraakt.

Je moet goed investeren in de begeleiding van de politieambtenaren. Je kunt niet alleen met de politieopleiding volstaan als je voor moeilijke maatschappelijke problemen komt te staan. Het is echter de vraag of men wel doorheeft op welk niveau de politieman momenteel moet functioneren en met wie samengewerkt moet worden. Vaak zijn dat mensen die een veel hoger opleidingsniveau hebben. Het is niet altijd zo eenvoudig om anderen van je gelijk te overtuigen. Daar komt nog bij dat de politie geïntegreerd moest gaan werken, met allerlei instellingen en diensten. Anders loop je eenzaam achter de problemen aan. Als je niet samen met anderen, ook preventief, probeert te werken, ben je als politieambtenaar zo machteloos. Er is nu een streven om veel meer mensen van buiten binnen te halen. Van universiteiten en mensen met andere kennis. Er worden nu ook geprobeerd om ouderen, met een brede maatschappelijke ervaring, binnen te halen. Het is ook goed dat er meer vrouwen zijn gekomen. Jonge vrouwen zijn geestelijk vaak verder dan jonge mannen.

Ik voel mij nog steeds heel betrokken bij de politie. Hoewel ik me op een aantal punten zorgen maak voor de toekomst, zie ik ook positieve ontwikkelingen. 